\title{
El derecho operacional como una categoría dentro de la taxonomía del derecho*
}

\author{
The Operational Law as a Category Inside the Taxonomy of Law
}

\author{
Francisco Alejandro Chiquiza Gómez ${ }^{\text {a }}$ \\ Escuela Militar de Cadetes "General José Maria Córdova", \\ Colombia \\ alejandro_chiquiza@hotmail.com \\ ORCID: http://orcid.org/0000-0001-9514-8080
}

Juan Fernando Gil Osorio

Escuela Militar de Cadetes "General José María Córdova", Colombia

ORCID: http://orcid.org/0000-0002-6605-6846
DOI: https://doi.org/10.11144/Javeriana.vj139.doct

Recepción: 23 Julio 2019

Aceptación: 12 Agosto 2019

Fecha de publicación: 30 Diciembre 2019

\section{Resumen:}

La presente investigación pretende reivindicar la importancia de construir, como objeto de estudio, una categoría del derecho denominada derecho operacional[1], con el fin de contribuir al debate socio-jurídico de las relaciones que se suscitan o se producen en las actuaciones de la fuerza pública, entendidas estas como las Fuerzas Militares y la Policía Nacional. En ese sentido, resulta completamente plausible construir todo un conocimiento alrededor de los imperativos normativos que reglan los procedimientos de las instituciones castrense y policial, respectivamente. Así, se procura realizar una aproximación a los ejes axiales o definitorios de esta ordenación jurídica y que, eventualmente, podría dar explicaciones profundas a fenómenos del entorno social y que se relacionan con la contención de las amenazas de una sociedad. Finalmente, el documento propone un análisis de validez y eficacia de las reglas operacionales, dada su raigambre administrativa, justificándolas como principio de lex artis de la ciencia, el arte de las operaciones militares y los operativos policiales.

Palabras clave: Derecho operacional, Fuerza Pública, Fuerzas Militares, Policía Nacional, derecho; procedimientos, política, constitución, norma, derechos humanos, derecho internacional humanitario, justicia transicional, reglas operacionales, validez, eficacia, derecho internacional de los conflictos armados, derecho administrativo, delegación, desconcentración, vinculante, lex artis, paz, hostilidades, planeación, integración normativa.

\section{Abstract:}

This investigation seeks to vindicate the importance of constructing, as an object of study, a category of law called operational law, to contribute to the socio-juridical debate of the relations that arise or occur in the actions of the Public Force, understood these as Military Forces and National Police. In that sense, it is entirely plausible to build complete knowledge around the normative imperatives that regulate the procedures of military and police institutions, respectively. Thus, an attempt is made to make an approximation to the axial or defining axes of this legal arrangement. Eventually, it could give in-deep explanations to phenomena of the social environment and that are related to the containment of the threats of society. Finally, the document proposes an analysis of the validity and effectiveness of the operational rules, given their administrative roots, justifying them as a principle of lex artis of the science and art of military operations and police operations.

Keywords: Operational law, Public Force, Military Forces, National Police, law, procedures, policy, constitution, norm, human rights, international humanitarian law, transitional justice, operational rules, validity, effectiveness, international law of armed conflicts, administrative law, delegation, deconcentration, binding, lex artis, peace, hostilities, planning, normative integration.

Notas de autor

\footnotetext{
${ }^{a}$ Autor de correspondencia. Correo electrónico: alejandro_chiquiza@hotmail.com
} 


\section{Introducción}

El objetivo de la presente investigación es sentar las bases para un estudio jurídico de lo que debe concebirse como "derecho operacional" aportando a que la definición de dicho concepto se desarrolle con una mejor claridad aclarando sus finalidades y su estatuto epistemológico.

El estudio de la praxis de la fuerza pública implica, necesariamente, realizar una aproximación a las disposiciones que regulan la actividad militar o policial desde su finalidad hasta el modo en que se operativiza la misma, dada su especial característica de coerción y el involucramiento de derechos humanos ${ }^{[2]}$.

En ese sentido, la presente investigación pretende, de manera tangencial, realizar un acercamiento a la noción de $\mathrm{DOPER}^{[3]}$, como un "tipo o categoría” de ordenamiento jurídico dentro de la taxonomía o clasificación del derecho, y analizar el contenido jurídico que lo compone y los hechos o actividades que pretende controlar.

No obstante, desde ya, es necesario realizar algunas precisiones: primero, este artículo pretende reflexionar sobre la naturaleza jurídica y los niveles de validez y eficacia de las disposiciones que regulan el proceder estrictamente operacional, por lo que no se realizarán análisis de las disposiciones que normativizan la actividad netamente administrativa, sin desconocer que estas influyen directa y sustancialmente en las operaciones militares y los operativos policiales. Segundo, para la valoración de las disposiciones, en este caso, se procurará realizar una reivindicación del DOPER como un conjunto de normas indispensables para entender distintos fenómenos o contextos en el marco de la conducción de hostilidades o el restablecimiento del orden público.

Este análisis en particular tiene una justificación estructural respecto de las operaciones militares y los operativos policiales, pero es a la vez coyuntural, ya que las reglas operacionales, según el acto legislativo 01 de $2017^{[4]}$, tienen la vocación de determinar la calificación jurídica de los integrantes de la fuerza pública por conductas cometidas por causa, con ocasión o en relación directa o indirecta con el conflicto armado interno en Colombia, en el contexto de la Jurisdicción Especial para la Paz (JEP).

Así las cosas, el constituyente derivado, al menos en principio, entendió la necesidad de comprender la dinámica institucional de la fuerza pública en el proceso de planeamiento, ejecución y evaluación de operaciones militares u operativos policiales para que el Sistema Integral de Verdad, Justicia, Reparación y No Repetición (SIVJRNR) pueda ofrecer un proceso de construcción de memoria completo. Lo que significa incluir las voces de todos los actores en el marco del conflicto armado interno y, a la vez, identificar las deficiencias en los procesos de toma de decisiones en la fuerza pública.

Lo anterior, destaca la ineludible responsabilidad de emprender un análisis sobre las prácticas y procedimientos operacionales y operativos para comprender las complejas dinámicas sociales que se suscitan en escenarios en los que se activan las capacidades y competencias de la fuerza pública. En contextos donde se presentan altos umbrales de violencia este análisis puede ayudar a ofrecer respuestas a los fenómenos que derivaron en macro-criminalidad y macro-victimización, de ahí que se haya incluido como imperativo de estudio en una disposición de rango superior ${ }^{[5]}$.

La metodología utilizada dentro del desarrollo del documento es de carácter cualitativa deductiva. Lo que da como resultado un documento de carácter mixto ya que el resultado de investigación gira entorno a la validez y eficacia del derecho operacional, pero también podría ubicarse en el campo de una reflexión académica con relación al concepto del derecho operacional. 


\section{Hacia una episteme del derecho operacional: naturaleza y conceptualización}

La construcción de una episteme del derecho operacional (DOPER implica, inexcusablemente, abordar el alcance de la misión constitucional asignada a la fuerza pública, ya que de ésta se desprenden las prácticas y procedimientos operacionales u operativos, se trate de las Fuerzas Militares o de la Policía Nacional, respectivamente. La Corte Constitucional en sentencia C-058 de 1994 señaló que:

"La fuerza pública no cumple únicamente sus funciones de manera armada, conforme al rol clásico de las fuerzas militares de protección de fronteras o de la Policía de preservación armada del orden interno, sino que el rol moderno de la fuerza pública puede ser más amplio" ${ }^{[6]}$.

Así, es aceptado por la doctrina constitucional democrática que la fuerza pública puede y debe intervenir en momentos, inclusive de graves catástrofes nacionales, a fin de efectuar labores de rescate y de apoyo, pero, como es obvio, subordinada a las directivas de las autoridades civiles y políticas.

En ese sentido, se amplía el margen de competencias y funciones asignadas a la fuerza pública. De la misma manera, es legítimo considerar que la fuerza pública puede cumplir sus objetivos constitucionales de manera desarmada, fuera de su marco tradicional clásico, por medio de actividades cívico-militares. En efecto, corresponde a las Fuerzas Militares garantizar "la integridad del territorio nacional" ${ }^{[7]}$ y a la Policía Nacional "mantener las condiciones necesarias para el ejercicio de los derechos y libertades públicas, y para asegurar que los habitantes de Colombia convivan en paz" ${ }^{[8]}$, por lo que es obvio que resulta legítimo que el Estado establezca políticas destinadas a asegurar una presencia efectiva de la fuerza pública dentro de todo el territorio nacional.

Esto significa que es constitucionalmente legítimo que la fuerza pública no sólo salvaguarde de manera armada el orden público interno y externo, sino que también participe en labores destinadas a incorporar de manera efectiva los territorios a la vida económica, social y política del país.

Por su parte, particularmente, las Fuerzas Militares están constituidas para la defensa de la soberanía, la independencia, la integridad del territorio nacional y el orden constitucional ${ }^{[9]}$, concepto que se mantiene desde las primeras manifestaciones de constitución en Colombia. Tal como se observa en el Acta de Confederación de las Provincias Unidas de la Nueva Granada del 27 de noviembre de 1811, en su artículo 11, donde se prescribió que la defensa común es uno de los objetivos principales de la unión, facultándose la creación de ejércitos para tal fin ${ }^{[10]}$.

Este concepto es una constante a lo largo de la historia constitucional colombiana ${ }^{[11]}$, así lo manifestaron, particularmente, la Ley Fundamental de la República de Colombia de 1819, en la Constitución Política de la República de Colombia de 1821, en la Constitución Política de la República de 1830, en la Constitución Política del Estado de Nueva Granada de 1832, en la Constitución Política de Nueva Granada de 1843, en la Constitución Política para la Confederación Granadina de 1858, en el Pacto de la Unión de 1861 y en la Constitución Política de la República de Colombia de 1886.

Tal como se puede observar en la tangencial referencia, el constituyente primario previó, desde siempre, una función unívoca para las Fuerzas Militares, misión que fue recogida de manera integral en el artículo 217 de la Constitución Política de 1991. Sin embargo, a esta función esencial, la Corte Constitucional ha adicionado como misión de las Fuerzas Militares, a través de la interpretación que ha hecho de la Carta Política, la búsqueda de la convivencia pacífica; la protección de los derechos humanos; y, en el marco del conflicto armado, la protección especial de las víctimas. Y finalmente, ha precisado que a las Fuerzas Militares les corresponde realizar labores de inteligencia ${ }^{[12]}$.

Respecto de la misión, expressis verbis, contemplada en el artículo 217 de la Constitución, es preciso señalar que se implica que las Fuerzas Militares "tienen el deber constitucional de garantizar que la soberanía y el orden constitucional no se vean alterados o menoscabados" ${ }^{[13]}$, tal como la Corte Constitucional lo indicó en 
la sentencia SU-1184 de 2001. Por su parte, el mismo tribunal señaló que el "soporte básico y fundamental" de esta función es la "defensa y protección de los derechos humanos" ${ }^{[14]}$.

De tal manera que, la función de las Fuerzas Militares en el Estado colombiano es holística y tiene como fin permitir la materialización de los derechos y libertades del conglomerado social, "garantizar las condiciones de seguridad colectivas y de carácter estructural" ${ }^{[15]}$. En consecuencia, la misión de las Fuerzas Militares no se limita a preservar la estructura democrática y a permitir que el Estado tutele el poder soberano, sino que comprende el deber de participar activa y eficazmente en la defensa de los derechos constitucionales de los asociados “(...) que constituyen los bienes respecto de los cuales el Estado (Fuerzas Militares) tiene el deber irrenunciable de proteger" ${ }^{[16]}$.

En ese sentido, conforme con la misión constitucional asignada a las Fuerzas Militares, todo aquello que represente un riesgo para preservar la estructura democrática, la capacidad de ejercer "el poder superior para mandar" ${ }^{\text {[17] }}$, la satisfacción de los derechos humanos y fundamentales de los asociados que impida la materialización de las libertades y reduzca las condiciones de seguridad representa una amenaza, debe ser, inexcusablemente, objeto de contención por parte de las Fuerzas Militares ${ }^{[18]}$.

Como resulta palmario, las responsabilidades asignadas a las Fuerzas Militares y a la Policía Nacional suponen un alto grado de especialidad que, tal como lo prevé el artículo 122 superior, debe tener sus funciones detalladas en la ley o reglamento alguno, las cuales, para el caso que ocupa el presente análisis, constituirían el contenido del DOPER.

Hablar de DOPER, entonces, implica hacer referencia a un extenso conjunto de disposiciones normativas que regulan las funciones de la fuerza pública, tanto las operaciones militares, como los operativos policiales, lo que resulta oportuno indicar que la construcción de esta tipología o categoría del derecho admite y, además exige, que esta se ubique desde una perspectiva de la ciencia del derecho.

En ese sentido, para efectos de analizar el concepto y alcance del DOPER, se procurará realizar una aproximación su naturaleza. Es decir, en principio, el derecho, como concepto general, se piensa como el conjunto de disposiciones jurídicas positivas que surge de la sociedad como producto cultural generado dentro de leyes que tienen la finalidad de regular las relaciones entre los miembros de esa sociedad —las personas- y de estas con el Estado.

Ahora bien, refiriéndose al ámbito de aplicación del DOPER como un conjunto de disposiciones regulatorias, resulta puntual señalar que estas constituyen aquellas destinadas a regular los procedimientos militares o policiales para la toma de decisiones, en cumplimiento de la misión constitucional asignada a la fuerza pública.

En consecuencia, el presente análisis obedece a la cuestión de qué ha sido establecido como derecho por un cierto sistema, particularmente, el DOPER, partiendo del supuesto prestablecido por la ciencia del derecho ${ }^{[19]}$, la cual tiene por objeto el estudio, la interpretación y sistematización de un ordenamiento jurídico determinado, tal como lo señaló Kant ${ }^{[20]}$.

Así, la ciencia del derecho ${ }^{[21]}$ como una herramienta metodológica que estudia el orden social en su integridad, esencialmente el derecho positivo (es decir, de las normas que están o han estado vigentes en los diferentes ordenamientos jurídicos) puede ofrecer una respuesta a la necesidad de construir un concepto del DOPER, ya que esta se encarga de ${ }^{[22]}$.

- La interpretación del derecho: que consiste en establecer el verdadero sentido y alcance de una o varias normas jurídicas, para extraer nociones generales que le permitan elaborar teorías, conceptos y construcciones jurídicas.

- La integración del derecho: mediante las construcciones jurídicas para las relaciones sociales no previstas expresamente en el derecho positivo.

- La sistematización: consistente en la ordenación coherente y lógica de acuerdo con ciertos criterios clasificatorios del conjunto de normas jurídicas.

- La aplicación del derecho. 
Con fundamento en los presupuestos de la ciencia del derecho y con el fin de integrar y sistematizar una nueva categoría de ordenación jurídica, puede afirmarse que el DOPER es una especialidad jurídica con influencia política, de naturaleza pública, que integra una variedad de disposiciones jurídicas de raigambre internacional, constitucional, legal y reglamentaria, con el fin de establecer imperativos normativos que regulen los procesos de toma de decisiones de la fuerza pública en cualquier tiempo, para la realización de operaciones militares u operativos policiales.

No obstante, en la práctica del ordenamiento jurídico colombiano, tal como se ha destacado en investigaciones previas ${ }^{[23]}$, el proceso de integración y concepción del DOPER no ha sido pacífico. En algunos casos este ha sido calificado como un derecho etéreo e inconcluso y, en algunos casos, inexistente o confuso con relación a otras categorías del derecho, tales como el DIH ${ }^{[24]}$ o el DICA ${ }^{[25]}$.

Sin embargo, contrario a las discusiones coyunturales sobre el tema y las hipótesis propuestas por la ciencia del derecho, resulta completamente plausible, y además necesario, admitir y reivindicar la concepción del DOPER como una noción distinta, pero no aislada sino integradora del DIDH, del DIH e inclusive del DICA, la cual debe pensarse como una taxonomía del derecho eminentemente técnica que regula los procesos de toma de decisiones militares y policiales para el planeamiento, preparación, ejecución, evaluación y seguimiento de las operaciones u operativos de la fuerza pública ${ }^{[26]}$.

Así las cosas, desde una visión jurídico-científica de las disposiciones que regulan las funciones de las Fuerzas Militares y la Policía Nacional, y dada su naturaleza constitucional y misión especialísima encargada, se justifica la existencia de una categoría dentro de la taxonomía del derecho, como objeto de estudio, que dé una respuesta socio-jurídica a los procesos de toma de decisiones militares y/o policiales. Particularmente, en la ordenación coherente y lógica de las s disposiciones referida, de acuerdo con criterios clasificatorios del conjunto de normas jurídicas.

En ese sentido, las características sui generis de las actuaciones de la fuerza pública y su complejidad a la luz de una variedad de disposiciones normativas de distinta jerarquía normativa tienen la capacidad de sentar las bases para la construcción de una episteme o conocimiento de las relaciones sociales, tanto horizontales como verticales, así como endógenas y exógenas en términos institucionales, que se suscitan en los procesos de toma de decisiones de la fuerza pública para el cumplimiento de la responsabilidad asignada por el constituyente originario.

Lo anterior no solo facilita la comprensión del entramado de disposiciones que regulan el proceder de la fuerza pública en términos de tecnicismo operacional u operativo, sino que legitima las actuaciones administrativas (operaciones militares $u$ operativos policiales del poder coercitivo, al ofrecer una respuesta al por qué, el cómo y el para qué de las mismas. En ello radica la relevancia del DOPER, como una categoría adicional del derecho público.

\section{Dinámica del Derecho Operacional: identificación de su contenido}

Teniendo en cuenta la relevancia que entraña la naturaleza del DOPER para comprender el funcionamiento de las instituciones castrense y policial, es preciso presentar algunas reflexiones sobre su dinámica en estos "establecimientos" ${ }^{[27]}$ de poder (coercitivo. Cabe destacar que, tanto las Fuerzas Militares y la Policía Nacional son entidades de derecho público, cuya función, en principio, está regulada por los imperativos normativos de la constitución ${ }^{[28]}$ y la ley ${ }^{[29]}$, ya que "la función administrativa está al servicio de los intereses generales y se desarrolla con fundamento en los principios de igualdad, moralidad, eficacia, economía, celeridad, imparcialidad y publicidad, mediante la descentralización, la delegación y la desconcentración de funciones".

En este escenario se deben realizar dos precisiones conceptuales sobre la forma en que la fuerza pública cumple la misión asignada por el constituyente originario, a saber: 
1) Respecto de la función administrativa, la competencia de ordenamiento del gasto es delegada por el presidente de la República en el Ministerio de Defensa y ésta, a su vez, es delegada por el presidente en las distintas unidades ejecutoras de cada fuerza. Es decir, en las del Ejército, la Armada, la Fuerza Aérea y la Policía Nacional.

En este caso, la función administrativa está regulada mutatis mutandis de manera similar con el resto de las instituciones del Estado. No obstante, está función está intrínsecamente relacionada con la función operacional u operativa de las instituciones castrense y policial, ya que de ella depende el apoyo logístico de sus actuaciones.

2) Por otro lado, está la función operacional u operativa, la cual se encuentra regulada, en principio y con las excepciones establecidas, en el artículo 91 superior ${ }^{[30]}$ por la desconcentración de funciones. Esta figura administrativa está definida en el artículo 8 de la Ley 489 de 1998, como la "radicación de competencias y funciones en dependencias ubicadas fuera de la sede principal del organismo o entidad administrativa, sin perjuicio de las potestades y deberes de orientación e instrucción que corresponde ejercer a los jefes superiores de la Administración, la cual no implica delegación y podrá hacerse por territorio y por funciones $(\ldots)^{[31] ”}$

$\mathrm{Al}$ respecto, la jurisprudencia ha identificado las características de esta figura y ha precisado, entre otras, que:

“(...) (i) es una atribución de la competencia realizada por el mismo ordenamiento jurídico; (ii) tal atribución es realizada a un órgano medio o inferior dentro de la jerarquía; (iii) la competencia desconcentrada se confiere de forma exclusiva al órgano designado por el ordenamiento; (iv) la responsabilidad del superior jerárquico se circunscribe al ámbito de los poderes de supervisión propios de la relación jerárquica y; (v) el superior sólo puede reasumir la competencia previa una nueva atribución legal que así lo determine" ${ }^{[32]}$.

En ese orden de ideas, la Corte Constitucional, en jurisprudencia reiterada, concluyó que a pesar de estar de por medio el fenómeno de la desconcentración, el superior jerárquico del funcionario sobre quien se ha desconcentrado una función no queda exento de responsabilidad por las acciones que el subordinado realice con ocasión de la función asignada, ya que subsiste una relación jerárquica legal que tienen como finalidad cumplir con la función administrativa, de conformidad con los principios constitucionalmente establecidos $^{[33]}$.

Teniendo claros los fenómenos administrativos que intervienen en la dinámica operacional y que ineludiblemente constituyen un paradigma orientador para los niveles en los que se toman las decisiones en la fuerza pública, resulta notorio, y por lo demás obvio, que la compleja misión de las Fuerzas Militares y la Policía Nacional, a priori, corresponde a una función estrictamente administrativa, encaminada a la satisfacción de los fines esenciales del Estado.

La anterior afirmación no significa que se están circunscribiendo los límites de la categoría del DOPER, la cual se ha indicado corresponde a todo el ordenamiento jurídico que impone normas de conducta para el proceso de toma de decisiones de las Fuerzas Militares y la Policía Nacional. Es por ello que, como se destacó en líneas previas, el DOPER está compuesto por la integración de una variedad de disposiciones normativas de raigambre o fuente diversa, pero que inexcusablemente sirven a los propósitos del cumplimiento de la función administrativa asignada a los órganos de seguridad objeto de la presente investigación.

Previo a continuar con el proceso de sistematización estrictamente normativa, resulta necesario referirse a la "política" como uno de los elementos determinantes que facilitan la comprensión del funcionamiento de la fuerza pública, esencialmente en lo relativo a la toma de decisiones para la realización de operaciones militares u operativos policiales, en el marco de la dinámica del DOPER.

Dicho ingrediente categórico y definitorio del DOPER, podría decirse, constituye uno de los ejes axiales de esta ordenación jurídica y, probablemente, es la sustancia reactiva de síntesis (jurídico-política) que produce confusión al interprete al momento de conceptualizar la noción de DOPER. Particularmente, porque está disipada por ideas de seguridad nacional, defensa nacional, intereses nacionales, progreso y desarrollo como justificantes de uso del poder coercitivo del Estado, ya sea en cualquiera de sus dimensiones funcionales.

Para el caso que ocupa este análisis, se propone como definición de política los asuntos de Estado o que concierne al Estado y que se atiende a través de políticas públicas. Esto pone en evidencia el proceso de 
aproximación a los principios y a la dinámica que rigen la relación entre la esfera política y la acción pública. Es decir, la esfera en que se funda el régimen político y el dominio en que se desenvuelven las políticas públicas ${ }^{[34]}$. Dicha relación supone cada una de las disposiciones y resoluciones que adopta el régimen político y la acción pública en sí misma.

Así las cosas, las políticas públicas representan las medidas adoptadas por el Gobierno nacional para atender un asunto público, en este caso, las situaciones de seguridad y defensa nacionales, el respeto por los DDHH y la prevención de infracciones al DIH en escenarios de conflicto armado, así como las adecuaciones institucionales para garantizar la no repetición desde la competencia propia del actuar militar o policial. En otras palabras, las medidas adoptadas por el ejecutivo para el cumplimiento de la misión constitucional atribuida a la fuerza pública.

Esas decisiones políticas adoptadas por el ejecutivo presidente de la República (Ministro de Defensa, irradian sustancialmente la definición del DOPER, otorgándole una peculiaridad voluble y volátil a esta ordenación jurídica porque, en la mayoría de los casos, definen los intereses nacionales, las medidas de protección y garantía a la seguridad y defensa nacionales e identifican y caracterizan la amenaza que será objeto de contención por parte de la fuerza pública.

No obstante, dicha influencia política no está libre de limitaciones normativas para el ejecutivo, pero, en todo caso, existe un amplio margen de discreción para definir la política pública de seguridad y defensa nacional que hace parte del ordenamiento jurídico integrante del derecho operacional y constituye un elemento central en los procesos militares y policiales de toma de decisiones.

En tal sentido, resulta necesario destacar que, para el caso colombiano, los contenidos programáticos de la carta política y los fines esenciales del Estado como imperativos del constituyente originario representan claros derroteros para definir los instrumentos de política, la identificación de los intereses nacionales y la materialización de los ideales de progreso y desarrollo.

En consideración al elemento político como ingrediente reactivo del DOPER, resulta pertinente señalar que la seguridad nacional y la defensa son temas que, aunque su definición no ha sido concertada, se consideran que hacen parte de la esencia misma de existencia de los Estados. En ese sentido, para José Manuel Ugarte, el concepto de Seguridad Nacional significa la estrategia Estatal mediante la cual se procura conjurar las amenazas que puedan pesar sobre los valores esenciales que hacen a la existencia e identidad del Estado, tales como independencia, soberanía, e integridad territorial de un Estado ${ }^{[35]}$. En el caso colombiano, la Corte Constitucional ha precisado que con relación al sistema de seguridad y defensa nacionales:

"Una de las finalidades básicas de las autoridades colombianas es la defensa de la integridad nacional y la preservación del orden público y de la convivencia pacífica, no sólo porque así lo establece expresamente el artículo $2^{\circ}$ de la Carta, sino además porque esos elementos son condiciones materiales para que las personas puedan gozar de sus derechos y libertades"[36].

Sin embargo, la Corte Constitucional explica a su vez que no cualquier ley de seguridad y defensa es legítima, pues ella debe respetar integralmente la Constitución y los compromisos internacionales asumidos por Colombia en materia de DD.HH. y de derecho humanitario ${ }^{[37]}$. Entonces, la posibilidad de imponer deberes en materia de orden público y defensa se encuentra además delimitada por la propia Constitución Política, que atribuye ese papel fundamentalmente a la fuerza pública.

Así, a las Fuerzas Militares corresponde la defensa de la soberanía, la independencia, la integridad del territorio nacional y del orden constitucional, mientras que la Policía debe mantener las condiciones necesarias para el ejercicio de los derechos y libertades públicas, y asegurar que los habitantes de Colombia convivan en paz. Esto significa que la garante de la convivencia ciudadana es la fuerza pública ${ }^{[38]}$.

De tal manera que, en Colombia, tal como lo establece la Constitución Política, la formulación de una política de seguridad y defensa nacional tiene condicionada su legitimidad al respeto del pluralismo y la participación democrática, como garantía del Estado constitucional. Esto establece la primera articulación en los niveles más altos de la estrategia como ordenación jurídica constitutiva del DOPER. 
En lo político, el proceso de toma de decisiones militares se encuentra regulado por varios niveles de la estrategia. El primero en su jerarquía es la estrategia nacional, definida por el presidente de la República o el Ministerio de la Defensa, la estrategia militar general que está en cabeza del comandante general de las Fuerzas Militares y los comandantes del Ejército, la Armada, la Fuerza Aérea y la Policía Nacional. Por último, la estrategia militar operativa se desagrega en las Unidades Operativas Mayores ${ }^{[39]}$, Menores ${ }^{[40]}$ y Tácticas ${ }^{[41]}$.

La materialización de dichas estrategias está en los planes nacionales de desarrollo, plan estratégico sectorial, plan estratégico institucional, planes de guerra y planes de campaña estrechamente articulados. $A$ priori, se puede observar que los procesos de toma de decisiones en las Fuerzas Militares están absolutamente reglados y distribuidos de manera vertical de acuerdo con el nivel e impacto de la decisión que se toma, inclusive en el ámbito operacional.

Así, dependiendo del valor del objetivo militar para el desarrollo de la operación, el DOPER interviene al nivel de la estrategia correspondiente. Para efectos del desarrollo de operaciones militares u operativos policiales, la fuerza pública tiene delimitados procedimientos de toma de decisiones en todos los niveles que les permite actuar conforme a la misión para la cual fueron concebidas y sujetadas a los objetivos estratégicos definidos en el Plan Nacional de Desarrollo, Plan Estratégico Sectorial, Plan Estratégico Institucional, Plan de Guerra o Plan de Campaña. Estos constituyen la observancia al elemento político del DOPER, sin olvidar los demás ingredientes que integran esta tipología del derecho.

No obstante, como se mencionó, dicha política se fundamenta en la idea de interés nacional, el cual, según el constructivismo, corresponde a un concepto que escapa a las realidades materiales para convertirse en construcciones sociales. Por ello, para el constructivismo, el interés nacional es el resultado "de ideas compartidas, identidad nacional y prácticas normativas. Lejos por tanto de ser un concepto estático, los intereses nacionales de los Estados se forman dentro de un contexto cultural como resultado de la interacción social" ${ }^{[42]}$, reivindicando la transformación y adaptación constante del DOPER aplicable a las actuaciones de la fuerza pública.

En conclusión, el responsable de la dirección del poder coercitivo (fuerza pública) es el presidente de la República, quien, interpretando la Constitución Política, determina los objetivos de la política de seguridad y defensa y asigna los recursos que sean necesarios para alcanzar o mantener las capacidades del Estado ${ }^{[43]}$, siendo el primer intérprete genuino del derecho operacional.

Por su parte, el nivel de la estrategia militar o policial general recae sobre el comandante general de las Fuerzas Militares o del director de la Policía Nacional, conforme a las directrices gubernamentales expresadas por el presidente de la República en su política de defensa y estrategia de seguridad nacional. En este nivel se configura una estrecha relación entre la voluntad política y el propio arte de planear y conducir las operaciones militares o los operativos policiales.

Un tercer nivel de la estrategia militar es el operativo que le corresponde a quienes ejecutan las operaciones o los operativos, es decir, corresponde directamente a los comandantes de las unidades donde se realizan las actuaciones de la fuerza pública. En este nivel se planea y conduce la maniobra utilizando operaciones conjuntas o autónomas, en su respectivo nivel, para garantizar el empleo táctico, con relación a los objetivos estratégicos ${ }^{[44]}$.

En ese sentido, la toma de decisiones en el nivel estratégico operacional es tanto un arte como una ciencia, ya que involucra las capacidades propias de la fuerza pública, como movimientos aéreos, motorizados, a pie, el consumo de combustible, los efectos de las armas, los efectos del liderazgo, el grado de dificultad de las operaciones y la incertidumbre relacionada con las intenciones del enemigo ${ }^{[45]}$. Estos escenarios de la estrategia corresponden a una secuencia analítica, singular, sistemática y comprobada de variables normativas, políticas y fácticas que en su integridad constituyen el DOPER.

Todo este proceso de planeación estratégica que surge en lo nacional y llega hasta el territorio es el resultado de una serie de actuaciones administrativas complejas (actos administrativos y operaciones administrativas), 
que a su vez son derivación de actuaciones administrativas previas o de trámite que dan sustento a aquellas. Estas tienen una influencia política y la vez normativa que regulariza la función de las Fuerzas Militares y la Policía Nacional.

En todo caso, la materialización de la función de la fuerza pública es el resultado de procedimientos administrativos complejos, verticales y horizontales, los cuales en su integridad constituyen la tipología o categoría del DOPER como un ordenamiento jurídico sistematizado.

Con relación a las disposiciones normativas (influencia jurídica que definen el DOPER, la Procuraduría General de la Nación indicó que "es el cuerpo normativo que regula la conducción de hostilidades y otras misiones militares en tiempos de transición, de estabilización o de paz, en cuanto al uso de los medios y métodos" ${ }^{[46]}$, tema que va ligado ineludiblemente a las condiciones de orden público y a tratados vinculantes que ha suscrito el Estado colombiano y con los DD.HH y el Derecho Internacional Humanitario.

Por su parte, el artículo 4 del Decreto 124 de 2014 y la doctrina jurídico operacional, señalan que

"corresponde a la integración de los tratados internacionales ratificados por Colombia, la legislación nacional y la jurisprudencia en materia de Derechos Humanos y Derecho Internacional Humanitario al planeamiento, ejecución y seguimiento de las operaciones, operativos y procedimientos de la fuerza pública" ${ }^{\text {"[ }}$ "7].

Una explicación más extensa podría ser la propuesta en investigaciones previas, en las que se indicó que:

"El DOPER se encarga de estudiar, analizar, comprender e interpretar, desde la perspectiva de las operaciones militares, los siguientes temas (...): uso de la fuerza; medios y métodos de conducción de hostilidades; reglas de enfrentamiento; rol de los asesores jurídicos operacionales; límites a la conducción de hostilidades; niveles de responsabilidad en la conducción de hostilidades; objetivo militar y blanco lícito; dignidad humana; ambiente operacional y contexto; juez natural de los integrantes de la fuerza pública; importancia de los estados o planas mayores; y, el procedimiento para la toma de decisiones" ${ }^{[48]}$.

Teleología que se mantiene, pero que se considera que allí no se agota. En todo caso, al ser una tipología del derecho, como objeto de estudio, se estima inoportuno establecer un listado de las situaciones complejas que regulara el DOPER, razón por la cual se dirá que este constituye todas las disposiciones normativas aplicables a las actuaciones in genere de la fuerza pública. Se instituye dada su especialidad, en lex specialis,sin perjuicio de la jerarquía normativa que le corresponda a cada una de las disposiciones aplicables a las situaciones en concreto.

$\mathrm{Y}$ es que esta categoría del derecho ha surgido como consecuencia de un derecho positivo y consuetudinario, sustentado en el corpus iuris del Derecho de la Haya sobre medios y métodos de conducción de hostilidades. Estállamado a ser una ordenación jurídica que genere garantías tanto a la institución castrense como policial, además de que se establezca como una garantía de no repetición y prevención del daño antijurídico.

De esta manera, el DOPER como objeto de estudio representa una especialidad jurídica con influencia política, de naturaleza pública, que integra una variedad de disposiciones jurídicas de raigambre internacional, constitucional, legal y reglamentaria, con el fin de establecer imperativos normativos que regulan los procesos de toma de decisiones de la fuerza pública en cualquier tiempo, para la realización de operaciones militares $\mathrm{u}$ operativos policiales.

En este escenario, podría criticarse la falta de definición o referencia a las disposiciones normativas que estrictamente constituyen la ordenación jurídica del DOPER; sin embargo, el presente análisis no pretende llenar de contenido esta tipología, sino reivindicar su existencia como objeto de estudio y comprensión de la dinámica de la fuerza pública.

No obstante, en gracia de discusión, la definición es completa y suficiente si se considera que el objetivo de esta categoría del derecho es explicar el tecnicismo operacional y operativo y no la construcción de un nuevo derecho. En ese sentido, se invita a una visión interpretativa distinta del derecho existente y oportuno para reglamentar las actuaciones militares o policiales. 


\section{Validez y eficacia de las reglas operacionales: constitucionalización en el marco del modelo de justicia transicional adoptado por Colombia}

El problema de la producción de las normas jurídicas dentro de un sistema jurídico, el cual a su vez incluye el de la validez de las normas jurídicas, supone una posición de principio de teoría y filosofía del derecho, que tiene importantes consecuencias teóricas y prácticas en la práctica social y jurídica.

Se hace necesario entonces tomar una postura teórica y filosófica clara del derecho, en relación con el concepto de norma jurídica, el cual entraña el concepto de validez de estas. Esto, a su vez, conlleva necesariamente a preguntar por el modo de producción jurídico-institucional de las normas. De este modo, tenemos que en un sistema jurídico es fundamental determinar en primer término, qué es norma jurídica, elemento básico y esencial del derecho, como el concepto de “célula" para la biología ${ }^{[49]}$. Esta problemática corresponde a la teoría de las normas y aborda la parte estática del derecho ${ }^{[50]}$.

El derecho no está compuesto por una sola norma sino por una pluralidad de normas jurídicas. En consecuencia, la segunda parte de la teoría del derecho es la que se refiere a la teoría del ordenamiento jurídico que aborda la dinámica de las normas ${ }^{[51]}$. En esta parte se encuentra el análisis de las antinomias jurídicas y el proceso para resolver la contradicción dispositiva.

Vista la estructura fundamental de la teoría del derecho, es claro que el primer problema fundamental del sistema jurídico operacional, es la determinación de ¿qué es una norma jurídica? ¿Cuándo una norma nace al ordenamiento jurídico?, o, en otros términos, ¿cuáles normas pertenecen y cuáles no al sistema jurídico? Este problema se encuentra analítica e intrínsecamente ligado al problema de la validez de la norma jurídica, es decir, como enunciados normativos jurídicos-positivos.

Esta característica propia de las normas jurídicas como válidas es lo que llevó a Hans Kelsen a afirmar que el derecho pertenece al mundo del "deber ser" y no al mundo del "ser", ya que la pregunta por el derecho es la pregunta por la validez de la norma jurídica, es decir, por la existencia deontológica, y no la pregunta por la existencia fenomenológica de las cosas ${ }^{[52]}$.

Esto condujo a que Kelsen sostuviera que por ello mismo la lógica formal no funciona para el derecho, por cuanto su finalidad es la constatación de una correspondencia con un fenómeno del mundo del ser, mientras que, en cambio, en el derecho de lo que se trata es de constatar si una norma es válida, es decir de si existe en el mundo del derecho o del "deber ser" y ello de acuerdo con aquellas reglas que estipulan y prevén los presupuestos para su producción jurídica ${ }^{[53]}$.

A este respecto, hay que recordar que el sistema jurídico se crea y se reproduce a sí mismo, y contiene, por tanto, normas que estipulan la forma de la reproducción de las normas jurídicas, las cuales Hart denomina "reglas secundarias"[54]. Así mismo, a este problema fundamental del derecho acerca de la determinación de la pertenencia o no de una norma a un sistema jurídico de conformidad con las normas o reglas previstas por el propio sistema para su reproducción, es lo que Hart identificó como el problema del reconocimiento de las normas jurídicas como tales ${ }^{[55]}$.

Así entonces, el derecho será válido siempre y cuando satisfaga los requisitos que se establecen para la producción del mismo derecho y que están señalados por las reglas de producción del derecho en la Constitución.

Para el caso de las reglas operacionales, estas se han juzgado como actos administrativos que ocupan una jerarquía inferior dentro del ordenamiento jurídico. Esta discusión fue planteada, en investigaciones anteriores, al señalar que, en:

(...) la doctrina militar (reglas operacionales) debería tener la vocación de contener el DOPER, pero en Colombia no sucede así, pues dicha regulación, si bien se manifiesta de manera jurídica (generalmente a través de manuales que son actos 
administrativos de muy bajo nivel, utilizando como referente la famosa pirámide de Kelsen), no recoge en la mayoría de oportunidades los aspectos esenciales de los derechos (...). ${ }^{[56]}$

Por otro lado, en el marco del modelo de justicia transicional adoptado por Colombia para la terminación del conflicto y la construcción de una paz estable y duradera y en el proceso de implementación del Acuerdo Final, particularmente, en lo relativo al Sistema Integral de Verdad, Justicia, Reparación y No Repetición (SIVJRNR), se suscitó una fricción argumentativa en cuanto a la validez y eficacia normativa de lo que se concibe como reglas operacionales.

Lo anterior, esencialmente, porque el constituyente derivado incorporó de manera transitoria, excepcional y transicional al ordenamiento jurídico el SIVJRNR ${ }^{[57]}$, el cual tiene la vocación de reparar integralmente a las víctimas del conflicto, satisfacer los derechos a la verdad y exigir una rendición de cuentas de los máximos responsables de la comisión de delitos que constituyen graves violaciones a los DD.HH. e infracciones al DIH.

En dicho instrumento normativo de naturaleza constitucional se definieron, entre otros asuntos, los criterios para la calificación jurídica de los miembros de la fuerza pública que cometieron delitos por causa, con ocasión o en relación directa o indirecta, del conflicto armado y se precisaron los elementos de atribución de responsabilidad por mando, incluyendo como ingrediente sustancial y paradigma orientador de estos fenómenos jurídicos llamado las reglas operacionales (...) en relación con el DIH siempre que ellas no sean contrarias a la normatividad legal ${ }^{[58]}$.

No obstante, en el contexto del juicio de constitucionalidad que se realizó por parte de la Corte Constitucional al Acto Legislativo 01 de 2017 ${ }^{[59]}$, las intervenciones ciudadanas que se oponían a la incorporación de las reglas operacionales como sustrato para la evaluación de la conducta de los integrantes de la fuerza pública, en el marco de la Jurisdicción Especial para la Paz (JEP), señalaron que:

"Las reglas operacionales no tienen rango legal y que además tergiversan el sentido protector del DIH. Lo anterior sustituye el deber del Estado de investigar, juzgar y sancionar las graves violaciones a los derechos humanos y las infracciones al DIH”[60].

Finalmente, en el mismo estadio jurisdiccional, el Ministerio de Defensa de Colombia indicó que la remisión al derecho operacional se explica porque la conducta de los miembros de la fuerza pública debe valorarse en el marco de las reglas que rigen la conducción de las hostilidades y del uso de la fuerza, que, en todo caso, se adecúan a los estándares internacionales, particularmente para determinar los criterios para calificar los delitos cometidos por los miembros de la fuerza pública cometidos en el marco del conflicto armado ${ }^{[61]}$.

Sin embargo, debe precisarse que las reglas operacionales en el marco del modelo de justicia transicional y particularmente de la JEP, tiene una virtualidad de rendición de cuentas. En ese sentido, para efectos de imputar responsabilidad a aquellos que tienen o tenían el deber de prevención, supervisión y sanción de los delitos que puedan o sean cometidos por sus subordinados es imperativo tener en cuenta las reglas operacionales de distribución y asignación del mando en la institución castrense, así como del área de responsabilidad asignada, con el fin de identificar roles, competencias, deberes y obligaciones de cada comandante, tal como lo indica el manual de conducción de operaciones del comando general de las Fuerzas Militares:

La delimitación clara de los distintos niveles de planeamiento y conducción de la guerra ayuda a precisar las actividades que se deben cumplir en los distintos escalones en el teatro de la guerra y en los teatros de operaciones; el establecimiento de niveles estratégicos, operativo y táctico permiten crear un marco útil en el ordenamiento de actividades, evita duplicidad de esfuerzos y asigna claras responsabilidades; la aplicación de estos niveles le facilita al comandante o los comandantes establecer un flujo operacional, distribuir los recursos y asignar las tareas. Cada nivel se define por los objetivos que busque alcanzar ${ }^{[62]}$.

De tal manera que el test de imputación de responsabilidad a un comandante se debe fundar, según el Acto Legislativo 01 de 2017, necesariamente en sus deberes objetivos de cuidado, conforme al nivel de mando, responsabilidad, actividades, competencias, roles y áreas asignadas dentro del contexto de la guerra. 
Tal consideración, permite apreciar objetivamente la conducta omisiva del o los comandantes y asimismo la posibilidad de reprocharla, conforme a las competencias, roles y áreas asignadas.

Así las cosas, el contexto transicional, para el cual el constituyente derivado se valió de las reglas operacionales, resulta limitado con relación a la vocación y virtualidad para las cuales se han construido dentro de las instituciones de la fuerza pública. Es decir, estas constituyen los principios categóricos y la guía principal para todo militar o policía en el desarrollo de operaciones u operativos, cualquiera que sea su naturaleza.

En ese sentido, la actividad de la fuerza pública es un acontecer reglado, sujeto a normas y limitaciones, a las cuales el militar o policía debe someter su comportamiento, teniendo en cuenta la especificidad y peculiaridad del ejercicio del poder coercitivo del Estado. No obstante, como se afirmó y, posteriormente, fue acentuado por las intervenciones ciudadanas, las reglas operacionales tienen naturaleza administrativa y no legal en un principio, por lo que su nivel de vinculatoriedad podría verse reducido.

Sin embargo, debe destacarse que incluso la producción normativa de las reglas operacionales o la doctrina que será constitutiva de DOPER tienen características sui generis, no tanto con relación a las reglas secundarias o de producción, sino en cuanto a su proceso de reconocimiento por sus destinatarios, que, en este caso, son los propios integrantes de la fuerza pública, dotando de carácter vinculante, válido y efectivo a las reglas operacionales.

Entonces, mutatis mutandis, la doctrina y las reglas operacionales resultan siendo vinculantes, válidas, efectivas y admisibles, en tanto el uso de los conceptos allí plasmados sean determinables en forma razonable. Esto significa que es posible concretar su alcance, en virtud de remisiones normativas o de criterios técnicos, lógicos, empíricos, o de otra índole, que permiten prever, con suficiente precisión, el alcance de los comportamientos prohibidos y sancionados del proceder de los militares y policías en las actuaciones de la fuerza pública ${ }^{[63]}$.

Puede admitirse entonces que para efectos de la concreción de los conceptos indeterminados se acuda a las reglas que cada profesión tiene para su buen hacer o Lex Artis. En este caso de la fuerza pública, en su esencia cambiante por su propia naturaleza renovadora, que surge de experiencias y costumbres, marcan un especial modo de actuar y entender las reglas respectivas y propias de las Fuerzas Militares y la Policía Nacional ${ }^{[64]}$.

Ahora bien, si los conceptos y asuntos regulados en la doctrina y en las reglas operacionales no ofrecen determinación de los procedimientos militares y policiales a tal punto que no puede ser concretado en forma razonable, entonces dichos conceptos desconocen el principio de legalidad y por consiguiente perderán su fuerza vinculante.

Esto es la lex artis que se traduce en una forma de concreción de la remisión normativa a la que, por ejemplo, la Corte Constitucional se refirió en sentencia C-860 de 2006, así:

(...) "la lex artis, es la utilización de criterios técnicos, lógicos, empíricos, o de otra índole, que permitan prever, con suficiente precisión, el alcance de los comportamientos permitido, prohibidos y sancionados" ${ }^{\mathrm{6}[5]}$.

En consecuencia, la expresión lex artis -literalmente, "ley del arte"-, tal como lo señaló el Consejo de Estado, se emplea para referirse a un cierto sentido de apreciación sobre si la tarea ejecutada por un profesional es o no correcta o se ajusta o no a lo que debe hacerse ${ }^{[66]}$. Resulta completamente razonable y sensato señalar que las reglas operacionales constituyen la lex artis como principio de la fuerza pública, ya que sus actuaciones requieren de una técnica operativa que plasman en la práctica unos resultados empíricos, que hacen a estas disposiciones normativas completamente válidas y eficaces en el entorno jurídico y en la ordenación del DOPER. 


\section{Conclusiones}

El análisis previo y tangencial permite reivindicar la existencia del DOPER como una categoría adicional dentro de las distintas ramas del derecho. No obstante, esto no supone la creación o positivización de un catálogo distinto de disposiciones normativas para reglamentar las conductas de la fuerza pública, pese a que muchas de estas son cambiantes dada la especialidad y peculiaridad de su función.

En ese sentido, dicha categoría del derecho supone la integración de una variedad compleja de disposiciones normativas de distinta fuente jurídica, con el fin de comprender los alcances de las actuaciones militares o policiales. Así, este ordenamiento jurídico que se origina y promueve en una situación coyuntural, plantea a la academia un nuevo escenario de análisis, estudio y reflexión.

Se destaca que la clasificación del DOPER dentro de la sistemática jurídica constituye una subdivisión de divisiones más grandes del derecho y solo se justifica como objeto de estudio y de compresión de las relaciones socio-jurídicas que se producen en el seno de las instituciones militares y policiales, entre estas y la sociedad civil, otros organismos de seguridad, otros Estados, grupos armados organizados o grupos armados delincuenciales, entre otras.

Lo anterior es así en tanto la intervención de la fuerza pública y la forma en que lo hace pueda explicar en gran medida fenómenos sociales, políticos, económicos, culturales y operacionales en situaciones de altos umbrales de violencia o, inclusive, en escenarios ausentes de conflictividad o en paz.

El DOPER es un ordenamiento jurídico especializado de naturaleza pública con influencia política, constituido por un conjunto de normas de raigambre convencional, constitucional, legal y reglamentario que regula las actuaciones de las Fuerzas Militares y la Policía Nacional en todo momento, ya sea en conflictos armados o en escenarios de paz. Lo anterior justifica su estudio, incorporación y comprensión, no sólo de los integrantes de la fuerza pública, sino de la comunidad académica y profesional, en los ámbitos del derecho, la ciencia política, la sociología y la antropología.

\section{Bibliografía}

Carlos Bernal Pulido, Gerardo Barbosa Castillo \& Andrés Rolando Ciro Gómez, Justicia transicional: el papel de las fuerzas armadas. Ed. Universidad Externado de Colombia, 116 (2016.

Alf Ross, A. (1994. Sobre el Derecho y la Justicia., Ed. Buenod Aires: Eudeba. (1994.

Carlos Restrepo Piedrahita (compilador, Constituciones Políticas Nacionales de Colombia, Ed. Universidad Externado de Colombia (2009.

Comando General de las Fuerzas Militares, Manual de derecho operacional, 3-41 (2015.

Comando General de las Fuerzas Militares, Manual de Estrategia Militar General, 3-4 (1997.

Congreso de la Republica de Colombia, Acto legislativo 01 del 04 de abril de 2017. Por medio del cual se crea un título de disposiciones transitorias de la constitución para la terminación del conflicto armado y la construcción de una paz estable y duradera y se dictan otras disposiciones. https://www.funcionpublica.gov.co/eva/gestornormativ o/norma.php?i $=80615$

Congreso de la Republica de Colombia, Comunicado No. 01. (4 de abril, 2017). http://es.presidencia.gov.co/normativa/normativa/ACTO\%20LEGISLATIVO\%20N\%C2\%B0\%200 1\%20DE\%204\%20DE\%20ABRIL\%20DE\%202017.pdf

Constitución Política de Colombia [Const]. Art. 209. 7 de julio de 1991 (Colombia).

Constitución Política de Colombia [Const]. Art. 217.7 de julio de 1991 (Colombia).

Constitución Política de Colombia [Const]. Art. 91.7 de julio de 1991 (Colombia).

Corte Constitucional de Colombia. Sentencia C-058 de 1994 , C-058 (M.P. Alejandro Martínez Caballero, 17 de febrero de Corte Constituciona Colombiana 1994). 
Corte Constitucional de Colombia. Sentencia C-205 de 2005 (M. P. Jaime Córdoba Triviño, 8 de marzo de 2005).

Corte Constitucional de Colombia. Sentencia C-251 de 2002 (M. Ps. Eduardo Montealegre Lynett y Clara Ines Vargas Hernández, 11 de abril de 2002).

Corte Constitucional de Colombia. Sentencia C-406 de 2014 (M. P. Jorge Iván Palacio Palacio, 26 de junio 2014).

Corte Constitucional de Colombia. Sentencia C-530 de 2003 (M. P. Eduardo Montealegre Lynett, 2003).

Corte Constitucional de Colombia. Sentencia C-674 de 2017 (M. P. Luis Guillermo Guerrero Pérez, 14 de noviembre de 2017).

Corte Constitucional de Colombia. Sentencia C-782 de 2003 (M. P. Alfredo Beltrán Sierra, 10 de septiembre de 2003).

Corte Constitucional de Colombia. Sentencia C-860 de 2006, (M. P. Humberto Antonio Sierra Porto, 18 de octubre de 2006).

Corte Constitucional de Colombia. Sentencia SU-1184 de 2001 (M. P. Eduardo Montealegre Lynett, 13 de noviembre de 2001).

Daniel Giraldo Laíno, Lex Artis y Malpraxis (30 de agosto, 2018). https://www.geosalud.com/malpraxis/lexartis.htm Ejército Nacional de Colombia, Manual de Estado Mayor y Operaciones, 3-50 (2005).

Francisco Alejandro Chíquiza Gómez, Análisis de la política pública de operaciones militares: garantías de no repetición del daño antijurídico (2017) (tesis de maestría, Universidad Externado de Colombia).

Hans Kelsen, Contribuciones a la Teoría pura del derecho, Ed. Fontamara, 52-60, 62-65 (1 ${ }^{\text {ra }}$ ed., 1992).

Hans Kelsen, Teoría pura del derecho, Ed. Eudeba (1934).

Herbert L. A. Hart. El concepto del derecho, Ed. Abeledo-Perrot, 99-125 (Genaro R. Carrió trad., 1961)

Immanuel Kant, Fundamentación de la metafísica de las Costumbres (Pedro M. Rosario Barbosa ed., 2007)

Jean Bodin, Les six livres de la République: un abrégé du texte de l'édition de Paris de 1583, 74 (Ed. Libraire génerale francaise, 1993).

Jean Carlo Mejía Azuero, El contexto en Colombia: ¿un trasplante plausible desde el derecho internacional, en Gerardo Barbosa Castillo \& Carlos Bernal Pulido, El análisis de contexto en la investigación penal: crítica del trasplante del derecho internacional al derecho interno, 474 ( $1^{\text {ra }}$ ed., 2015).

Jesús Escandón Alomar, La concepción de la ciencia del derecho y el concepto de derecho vigente en el pensamiento Jurídico de Alf Ross, 12 Revista de derecho de la Universidad de Concepción, 168-174 (2001). http://mingaonline.uac h.cl/pdf/revider/v12n2/art11.pdf

Jose Manuel Ugarte, Los conceptos de defensa y seguridad en América Latina: sus peculiaridades respecto de los vigentes en otras regiones, y las consecuencias políticas de tales peculiaridades, Latin American Studies Association (2001). https://www.lasa.international.pitt.edu/Lassa2001/UgarteJoseManuel.pdf

Jurisdicción especial para la paz (JEP), Sistema integral de verdad justicia reparación y no repetición (2017). https:// www.jep.gov.co/Paginas/JEP/Sistema-Integral-de-Verdad-Justicia-Reparacion-y-NoRepeticion.aspx

Ley 489 de 1998. Por la cual se dictan normas sobre la organización y funcionamiento de las entidades del orden nacional, se expiden las disposiciones, principios y reglas generales para el ejercicio de las atribuciones previstas en los numerales 15 y 16 del artículo 189 de la Constitución Política y se dictan otras disposiciones. 29 de diciembre de 1998. D.O. No. 43464. https://www.funcionpublica.gov.co/eva/gestornormativo/norma.php?i=186

Norberto Bobbio, Teoría general del derecho. Ed. Temis, 135-145 (5. a ed., 2016).

Pedro Medellín Torres, La política de las políticas públicas: propuesta teórica y metodológica para el estudio de las políticas públicas en países de frágil institucionalidad. Ed. Naciones Unidas, División de Desarrollo Social, 5 (2005).

Procuraduría General de la Nación, Concepto 178 (2012).

Rubén Herrero de Castro, El concepto de interés nacional. En Evolución del concepto de interés nacional, 17-38 (Ed. Centro Superior de Estudios de Defensa Nacional, 2010). 


\section{Notas}

* Artículo de investigación. La investigación está vinculada al proyecto de investigación Observatorio de Derecho Operacional, de la Escuela Militar de Cadetes "General José María Córdova”, Colombia; vinculado al grupo de investigación "Ciencias Militares”, reconocido y categorizado en (B por COLCIENCIAS, registrado con el código COL0082556.

[1] En adelante DOPER

[2] En adelante DDHH.

[3] Derecho operacional.

[4] Congreso de la Republica de Colombia, Acto legislativo 01 del 04 de abril de 2017. Por medio del cual se crea un título de disposiciones transitorias de la constitución para la terminación del conflicto armado y la construcción de una paz estable y duradera y se dictan otras disposiciones.

[5] Íd.

[6] Corte Constitucional de Colombia. Sentencia C-058 de 1994 (M.P. Alejandro Martínez Caballero, 17 de febrero de 1994 ).

[7] Constitución Política de Colombia [Const]. Art. 217.7 de julio de 1991 (Colombia).

[8] Constitución Política de Colombia [Const]. Art. 218. 7 de julio de 1991 (Colombia).

[9] Supra nota 7.

[10] Carlos Restrepo Piedrahita (compilador), Constituciones Políticas Nacionales de Colombia, Ed. Universidad Externado de Colombia (2009).

[11] Francisco Alejandro Chíquiza Gómez, Análisis de la política pública de operaciones militares: garantías de no repetición del daño antijurídico (2017) (tesis de maestría, Universidad Externado de Colombia).

[12] 3 Carlos Bernal Pulido, Gerardo Barbosa Castillo \& Andrés Rolando Ciro Gómez, Justicia transicional: el papel de las fuerzas armadas. Ed. Universidad Externado de Colombia, (2016).

[13] Corte Constitucional de Colombia. Sentencia SU-1184 de 2001 (M. P. Eduardo Montealegre Lynett, 13 de noviembre de 2001).

[14] Corte Constitucional de Colombia. Sentencia C-782 de 2003 (M. P. Alfredo Beltrán Sierra, 10 de septiembre de 2003 ).

[15] Carlos Bernal Pulido, Gerardo Barbosa Castillo \& Andrés Rolando Ciro Gómez, op. cit., 116.

[16] Íd., 11 .

[17] Jean Bodin, Les six livres de la République: un abrégé du texte de l'édition de Paris de 1583, 74 (Ed. Libraire génerale francaise, 1993).

[18] Francisco Alejandro Chíquiza Gómez, supra nota 8.

[19] Jesús Escandón Alomar, La concepción de la ciencia del derecho y el concepto de derecho vigente en el pensamiento Jurídico de Alf Ross, 12 Revista de derecho de la Universidad de Concepción, 168-174 (2001).

[20] Immanuel Kant, Fundamentación de la metafísica de las Costumbres (Pedro M. Rosario Barbosa ed., 2007). Immanuel Kant nació en 1724 y murió en 1804, filósofo alemán, considerado por muchos como el pensador más influyente de la era moderna. La filosofía kantiana, llamada por su autor Idealismo Trascendental, es conocida entre nosotros también como filosofía crítica o "criticismo".

[21] La ciencia del derecho constituye un conjunto orgánico de disciplinas que estudian en forma ordenada y sistemática esa disciplina que se llama "derecho".

[22] Alf Ross, Sobre el Derecho y la Justicia, Ed. Eudeba (1994). 
[23] Jean Carlo Mejía Azuero, El contexto en Colombia: ¿un trasplante plausible desde el derecho internacional, en Gerardo Barbosa Castillo \& Carlos Bernal Pulido, El análisis de contexto en la investigación penal: crítica del trasplante del derecho internacional al derecho interno, 474 (1ra ed., 2015).

[24] El Derecho Internacional Humanitario.

[25] El Derecho Internacional de los Conflictos Armados.

[26] Supra nota 25.

[27] Esta referencia se hace al margen del sentido técnico y normativo que prevé el ordenamiento jurídico colombiano.

[28] Constitución Política de Colombia [Const]. Art. 209. 7 de julio de 1991 (Colombia). Artículo 209. La función administrativa está al servicio de los intereses generales y se desarrolla con fundamento en los principios de igualdad, moralidad, eficacia, economía, celeridad, imparcialidad y publicidad, mediante la descentralización, la delegación y la desconcentración de funciones. Las autoridades administrativas deben coordinar sus actuaciones para el adecuado cumplimiento de los fines del Estado. La administración pública, en todos sus órdenes, tendrá un control interno que se ejercerá en los términos que señale la ley.

[29] Ley 489 de diciembre 29 de 1998. Por la cual se dictan normas sobre la organización y funcionamiento de las entidades del orden nacional, se expiden las disposiciones, principios y reglas generales para el ejercicio de las atribuciones previstas en los numerales 15 y 16 del artículo 189 de la Constitución Política y se dictan otras disposiciones. 29 de diciembre de 1998. D.O. No. 43464.

[30] Constitución Política de Colombia [Const]. Art. 91.7 de julio de 1991 (Colombia).. En caso de infracción manifiesta de un precepto constitucional en detrimento de alguna persona, el mandato superior no exime de responsabilidad al agente que lo ejecuta. Los militares en servicio quedan exceptuados de esta disposición. Respecto de ellos, la responsabilidad recaerá únicamente en el superior que da la orden.

[31] Ley 489 de 1998, 29 de diciembre de 1998. D.O. No. 43464. Artículo 8.

[32] Corte Constitucional de Colombia. Sentencia C-205 de 2005 (M.P. Jaime Córdoba Triviño, 8 de marzo de 2005).

[33] Corte Constitucional de Colombia. Sentencia C-205 de 2005 (M.P. Jaime Córdoba Triviño, 8 de marzo de 2005).

[34] Pedro Medellín Torres, La política de las políticas públicas: propuesta teórica y metodológica para el estudio de las políticas públicas en países de frágil institucionalidad. Ed. Naciones Unidas, División de Desarrollo Social, 5 (2005).

[35] Jose Manuel Ugarte, Los conceptos de defensa y seguridad en América Latina: sus peculiaridades respecto de los vigentes en otras regiones, y las consecuencias políticas de tales peculiaridades, Latin American Studies Association (2001).

[36] Corte Constitucional de Colombia. Sentencia C-251 de 2002 (M.Ps. Eduardo Montealegre Lynett y Clara Inés Vargas Hernández, 11 de abril de 2002).

[37] Íd.

[38] Corte Constitucional de Colombia. Sentencia SU-1184 de 2001 (M. P. Eduardo Montealegre Lynett, 13 de noviembre de 2001).

[39] Divisiones o sus equivalentes en otras fuerzas.

[40] Brigadas o sus equivalentes en otras fuerzas.

[41] Batallones.

[42] Rubén Herrero de Castro, El concepto de interés nacional. En Evolución del concepto de interés nacional, 17-38 (Ed. Centro Superior de Estudios de Defensa Nacional, 2010).

[43] Comando General de las Fuerzas Militares, Manual de Estrategia Militar General, 3-4 (1997).

[44] Comando General de las Fuerzas Militares, supra nota 37.

[45] Ejército Nacional de Colombia, Manual de Estado Mayor y Operaciones 3-50 (2005). 
[46] Procuraduría General de la Nación, Concepto 178 (2012).

[47] Comando General de las Fuerzas Militares, Manual de derecho operacional, 3-41 (2015).

[48] Jean Carlo Mejía Azuero, supra nota 21, 474.

[49] Sobre el concepto y la validez de las normas jurídicas ver Hans Kelsen, Contribuciones a la Teoría Pura del Derecho, Ed. Fontamara, 52-60, 62-65 (1 ra ed., 1992). Así mismo, Riccardo Guastini, Distinguiendo, estudios de teoria y metateoría del derecho, Editorial Gedisa, Barcelona, 1999, págs. 92-110, 307-343.

[50] Norberto Bobbio, Teoría general del derecho. Ed. Temis, 135-145 (5.a ed., 2016).

[51] Íd.

[52] Hans Kelsen, Teoría pura del derecho, Ed. Eudeba, 58 (1934).

[53] Sobre este tema consultar Hans Kelsen, Teoría pura del derecho, Ed. Eudeba (1934).

[54] Herbert L. A. Hart. El concepto del derecho, Ed. Abeledo-Perrot, 99-125 (Genaro R. Carrió trad., 1961).

[55] Íd., 101.

[56] Jean Carlo Mejía Azuero, supra nota 21.

[57] El Sistema Integral de Verdad, Justicia, Reparación y No Repetición fue creado por el punto 5 del Acuerdo de Paz y está compuesto por: (i) la Comisión para el Esclarecimiento de la Verdad, la Convivencia y la No Repetición; (ii) la Unidad de Búsqueda para Personas dadas por Desaparecidas; (iii) la Jurisdicción Especial para la Paz; (iv) las medidas de reparación integral para la construcción de paz y las garantías de no repetición. El Sistema tiene como finalidad consolidar un escenario institucional transitorio o temporal suficiente y apropiado para satisfacer los derechos de las víctimas del conflicto armado y contribuir en la reconciliación nacional. Los órganos que componen el Sistema deben trabajar de manera conjunta y coordinada con enfoque territorial, diferencial y de género. El Sistema está apoyado en medidas restaurativas y reparadoras que atienden las necesidades y la dignidad de las víctimas para satisfacer su derecho a la verdad plena, a la justicia, la reparación y la no repetición, y buscar el reconocimiento de responsabilidad de quienes participaron en el conflicto armado interno. Jurisdicción especial para la paz (JEP), Sistema integral de verdad justicia reparación y no repetición (2017).

[58] Congreso de la Republica de Colombia, Comunicado No. 01. (4 de abril, 2017).

[59] Corte Constitucional de Colombia. Sentencia C-674 de 2017 (M. P. Luis Guillermo Guerrero Pérez, 14 de noviembre de 2017).

[60] Íd. Intervención de Corporación Colectivo de Abogados Luis Carlos Pérez (CCALCP), Asociación Nacional de Víctimas de Crímenes del Estado (ASORVIMM) y Corporación Acción Humanitaria por la Convivencia la Paz del Nordeste Antioqueño (CAHUCOPANA)

[61] Íd.

[62] Ejército Nacional de Colombia, Manual de Estado Mayor y Operaciones, 25 (2005).

[63] Corte Constitucional de Colombia. Sentencia C-530 de 2003 (M. P. Eduardo Montealegre Lynett, 2003).

[64] Corte Constitucional de Colombia. Sentencia C-406 de 2014 (M. P. Jorge Iván Palacio Palacio, 26 de junio 2014).

[65] Corte Constitucional de Colombia.Sentencia C-860 de 2006, (M. P. Humberto Antonio Sierra Porto, 18 de octubre de 2006).

[66] Daniel Giraldo Laíno, Lex Artis y Malpraxis (30 de agosto, 2018). (Giraldo Laíno, 2018)

\section{Licencia Creative Commons CC BY 4.0}

Para citar este artículo/To cite this article: Francisco Alejandro Chíquiza Gómez \& Juan Fernando Gil Osorio, El derecho operacional como una categoría dentro de la taxonomía del derecho, 68 Vniversitas, n. ${ }^{\circ} 139$ (2019). https://doi.org/10.11144/Javeriana.vj139.doct 